\title{
SYSTEM ORIENTED SUSTAINABLE SUPPLY CHAIN MANAGEMENT INNOVATIONS IN AUTOMOTIVE INDUSTRY - SKODA AUTO CASE STUDY
}

System thinking and system theory are currently widely used in a variety of subjects and fields. Sustainability Supply Chain Management is defined as the strategic, transparent integration and achievement of an organization's social, environmental, and economic goals. The automotive industry is known as one of the most competitive branches in the industrial sphere. Efficient and effective deliveries of complete cars are fundamentally dependent on the performance of the delivery concept in the whole supply chain. The aim of the article is to research and define the fundamental principles and assumptions of system oriented innovations utilized in the Sustainable Supply Chain Management of automotive industry. These principles are derived on the basis of the case study related to the Efficient, Electronic, and Ecology Delivery Concept developed by SKODA AUTO Logistics.

Keywords: System thinking, Sustainable Supply Chain Management, Innovations, Automotive industry.

\section{Introduction}

The traditional approach to develop and implement innovations in automotive supply chain is based on productivity improvements of each individual part without considering the mutual interactions and the properties of the whole supply chain. Two critical assumptions of the proper system thinking application: improving mutual interactions between particular parts of the system and understanding of the essential properties of the wholes - systems, which derive properties of the parts and their interactions, haven not been applied either in academics nor practice so far. System thinking could rapidly increase the productivity of supply chain processes not only in automotive industry. The most important recent concept of Supply Chain Management (SCM) built by leading automotive companies is the sustainability. Practical example of Sustainable Supply Chain Management (SSCM) solution in automotive industry is Ecology, Efficient, Electronic and Ecology Delivery Concept (EDC) developed by SKODA AUTO Logistics (SAL). The aim of the article is to research and define the fundamental principles and assumptions of system oriented innovations derived on the basis of the EDC innovation in SKODA AUTO case study.

\section{Literature review}

\subsection{System thinking}

System thinking is one of the core methodological approaches to SCM research. Activities in organizations are best understood and developed when seen as an interaction of various subsystems and processes constituting a whole [1]. Based on the current practical experiences with social-economic systems (international teaching and research activities, solving practical projects for leading companies in the manufacturing industry) in SCM development including systems thinking utilization and literature research in understanding of systems thinking in relations to the wholes, in social system management, two attitudes could be identified:

Environmental free systems thinking - properties of the parts and their interactions creating the whole and deriving its properties without consideration for the environment.

Environmental full systems thinking - understanding of the essential properties of the whole by identifying its functions and properties in the containing (superior) system of which the examined system is a part. These essential properties derive the properties of the parts and their interactions. The environment is included.

The first attitude has dominated the theory and practice so far (from the introduction of General System Theory in 50's).

\footnotetext{
* Jiri Cee, Oleksii Dieiev, David Holman, Radim Lenort, David Stas, Pavel Wicher Skoda Auto, Mlada Boleslav, Czech Republic

E-mail: David.Holman@savs.cz
} 
It could be described either as self-centred orientation of social system management or fragmentation of the whole into individual parts and its separated management. In the supply chains, businesses, universities, governments, hospitals of any social system see the environmental free system thinking orientation as to divide the social system into parts, attempt to maximize the performance of the parts or their relations and hope that the sum and interactions will create an efficient whole, explicitly expressed by Christopher, one of the leading scientists in the branch of SCM in general. After almost 30 years of SCM concept development, he suggests a new direction of the concept, replacing the term SCM by demand chain management. Self-centred orientation of businesses and academic research should be replaced by customer-centred orientation, properties derived outside the system. Outside orientation has been seen only in the marketing departments so far and should be rolled out systematically to the whole supply chain [2]. The second attitude and its impact and implications have stood aside mainstream academic and practical attention so far. Particularly mentioned by Ackoff's: Systems thinking definition - the essential properties of the system are properties which none of its parts have, the essential properties are derived outside the system and could be seen only in the containing system [3].

\subsection{Supply Chain Management (SCM) in Automotive industry}

\subsubsection{Supply Chain Management}

Supply Chain Management encompasses the planning and management of all activities involved in sourcing and procurement, conversion, and all logistics management activities. Importantly, it also includes coordination and collaboration with channel partners, which can be suppliers, intermediaries, third-party service providers, and customers. In essence, supply chain management integrates supply and demand management within and across companies. Supply Chain Management is an integrating function with primary responsibility for linking major business functions and business processes within and across companies into a cohesive and high-performing business model. It includes all of the logistics management activities noted above, as well as manufacturing operations, and it drives coordination of processes and activities with and across marketing, sales, product design, finance and information technology [4]. Typical structure of Supply chain starts with final customer, who is delivered by final product or service. In general, the chain contains retailer, distributor, producer, logistics service provider, forwarder, supplier. Each of the chain is the semi-final customer of the previous chain. Each chain of the supply chain contains the inbound logistics flow (flow of resources into the production e.g. assembly line) and outbound logistics flow (flow of resources outside the chain e.g. delivery of final product to distributor, retailer or final customer). The concrete structure depends on the product, market or the particular strategy of the producer to complete customer demand.

\subsubsection{Specifics of SCM in automotive industry}

Automotive industry belongs to the leaders of innovation in the industrial sphere because of its complexity, production volumes, demanding customers and the worldwide competitive environment. The typical automotive supply chain contains thousands of $1^{\text {st }}, 2^{\text {nd }}$ and $3^{\text {rd }}$ tier suppliers, OEM's, distributors and dealers connected by forwarders, logistics services providers and cross-dock centres. The management of these chains in supply chain is characterised by integration, process management, logistics and production value added analysis and pull principle. The leading management system of innovations utilized in automotive supply chains in general is LEAN including tools and principles such as JIT, Kanban, SMED, Kaizen, 5S, Jidoka, Andon etc. Actual situation in automotive SCM, described later by Original delivery concept, haven't used the potential of LEAN improvement yet and have been still focused on particular optimization striving for short term, cost reduction results. Latest trends in automotive industry consider the impact of the production to the natural environment and the human labour. Together with serious accent to costs and productivity, there was defined the new SCM solution including efficiency, social aspects and natural environmentally friendly attitudes called Sustainable Supply Chain Management.

\subsubsection{Sustainable Supply Chain Management}

Although there is a divergence of definitions of sustainability, these differences are not too great. Most definitions of sustainability incorporate a consideration of environmental, economic, and social dimensions:

- Sustainability is a wise balance between economic development, environmental stewardship, and social equity [5].

- Sustainability includes equal weightings for economic stability, ecological compatibility and social equilibrium [6].

This definition is based on the Elkington's [7] triple bottom line (the intersection of environmental, social and economic performance) and the four supporting facets (facilitators) of SSCM [8]:

1. Strategy - holistically and purposefully identifying individual SSCM initiatives which align with and support the organization's overall sustainability strategy.

2. Risk management, including contingency planning for both the upstream and the downstream supply chain. 
3. An organizational culture, which is deeply ingrained and encompasses organizational citizenship and which includes high ethical standards and expectations along with a respect for society and the natural environment.

4. Transparency in terms of pro-actively engaging and communicating with key stakeholders and having traceability and visibility into upstream and downstream supply chain operations.

SSCM is the SCM concept oriented on balancing the economic, environmental and social supply chain performance.

\section{Case study - SKODA AUTO}

SKODA AUTO is a significant worldwide producer of cars. The daily production of 3,000 cars in the Czech Republic, need to be supported either by inbound flow of components or outbound flow of complete cars. The general numbers describing daily performance of the total inbound flow of resources are 2,500 trucks, 100 containers, 200 wagons. All the material flow must be supported by information flow and human resources considering the living and social environment. The case study is focused on inbound logistics flow of SCM.

\subsection{Original delivery concept}

The original delivery concept could be described by particular optimization of chains in supply chain focused on the lowest possible costs of each individual chain with limited coordination, cooperation and natural environment consideration. Based on the current state analysis the following problems have been defined:

1. Necessity to deal with an increasing number of truck deliveries, which are the result of both growing production and a rise in part numbers. The truck has to go through a tangled arrival process, making the route to the unloading area in the plant, or into the logistics centre more complicated. Furthermore, just-in-time and just-in-sequence deliveries are difficult to optimize due to the considerable paperwork and manual check-in processes.

2. Difficulties in optimization of the truck loading to achieve the optimum amount of materials in warehouses. Deliveries in this regard take place 2-3 times a day, thus the amount of material loaded on trucks should not exceed the specified maximum.

3. There is a need to unify two separate transport labels of $\mathrm{C}$ and $\mathrm{B}$ types in order to reduce the cost of printing, improve the time management among workers and spend less paper and ink to care about the environment.

4. Currently used trucks with diesel engines produce a lot of carbon dioxide, which is harmful to the environment. It is necessary to find a solution that corresponds to the diesel engine as far as technical characteristics, but is more sparing in relation to the environmental situation.

\subsection{Efficient, Electronic, and Ecology Delivery Concept}

The reaction of the SAL to above mentioned challenges in supply chain was proposal of system oriented solution including the SSCM elements. The new innovative concept (EDC) developed by SAL is based on the system oriented integration of the four pillars (see Fig. 1):

1. QCI (Quick Check-In) is the geo-fencing project, which involves a simple smartphone app that uses GPS technology to verify the position of incoming trucks, and connects to the control system for checking in material at the plant. The system allows trucks that adhere to delivery and production schedule to bypass the entry gate and move directly to the plant dock or the logistics centre adjacent to the factory without any extra paperwork or stopping [9].

2. FOLAB is the material requirement calculation program for delivery instructions which always runs once a week, now including the vehicle build-program for the 3rd production week in line. Single calls are shown in the delivery instructions from Monday of the following week. If no delivery has been recorded for the material requirement that was scheduled for a delivery date before the current requirement period, this will be entered as backlog in the delivery instruction. The total material amount entered as backlog and urgent requirement (plus any material requirement for the following delivery day) should be shipped immediately. If necessary, the mode of shipment should be agreed separately with the responsible material follow-up analyst [10].

3. GTL (Global Transport Label) was created in order to substitute the outdated system of separated B and C labels, constituents of VDA 4902 (Odette transport label). GTL has been created in accordance to ISO 15394. GTL label is the most universal solution to ensure a stable delivery in the transport chain from the supplier via the intermediate storage to the point of assembly or directly to the customer [11].

4. CNG (Compressed Natural Gas) is natural gas under pressure which remains clear, odourless, and non-corrosive. Although vehicles can use natural gas as either liquid or gas, most vehicles use the gaseous form. Natural gas is produced worldwide at relatively low cost and is cleaner than gasoline or diesel fuel. Natural gas vehicles show an average reduction in ozone-forming emissions of 80 percent compared to gasoline vehicles [12]. 


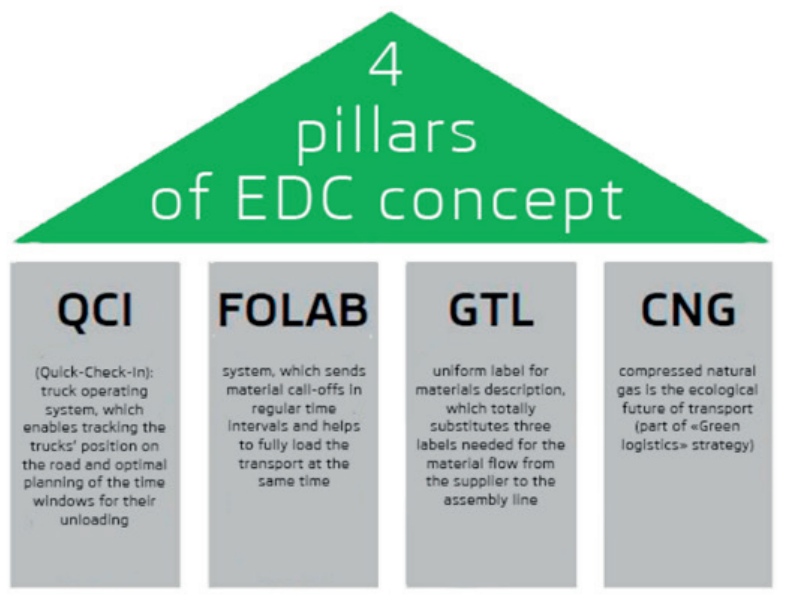

Fig. 1 Pillars of EDC concept [13]

The benefits of EDC against original delivery concept are [13]:

1. Logistics expenses, including fuel and pallets costs, are reduced by $25 \%$ in comparison with the existing system.

2. Expenses on material inventories are $55 \%$ lower.

3. Expenses associated with logistics space are also decreased by $55 \%$.

4. $\mathrm{CO}_{2}$ emissions are $50 \%$ lower through the use of $\mathrm{CNG}$ in trucks instead of diesel engine. Also reduction of $\mathrm{CO}_{2}$ emissions is caused indirectly by the use of the FOLAB system due to optimal loading of truck resulting to less number of round trips.

\section{Findings and discussion}

Based on the research and analysis of the case study, especially the EDC concept, two basic principles of environmental full system oriented innovations utilized in the SSCM in automotive industry could be defined:

1. Improving mutual interactions between particular parts of the system (P1):

- Efficient flow of active and passive components between particular chains in the supply chain.

- Integration of physical and non-physical resources in the SSCM system.

2. Derivation properties of interactions of SSCM from the essential properties of the SSCM system (P2):

- The essential properties of interactions of the whole SSCM were derived by the upper system in which the SSCM system is working - business markets and society conditions of $21^{\text {st }}$ Century. The list of properties which should be fulfilled is: the reduction of the negative impact on the natural environment, better working conditions, delivery quality, reasonable costs, and availability of resources, agility, and resilience.
- The performance (intensity of innovations) of interactions is derived from the essential properties of the SSCM system as a whole.

The particular optimization of separated chains in supply chain (suppliers, forwarders and SKODA AUTO plant was replaced by unified goal of all participants supported by improving of interactions (information and material flow) of all chain in inbound logistics supply chain. Instead of bottom up, the topdown approach was used to manage the quality and productivity of interaction between chains in supply chain and the productivity of the whole, inbound logistics system, rather than separated productivity of the each individual part.

Comparison of traditional and environmental full system oriented approach to innovations in SSCM is shown in Fig. 2.

\section{Traditional approach to innovations}

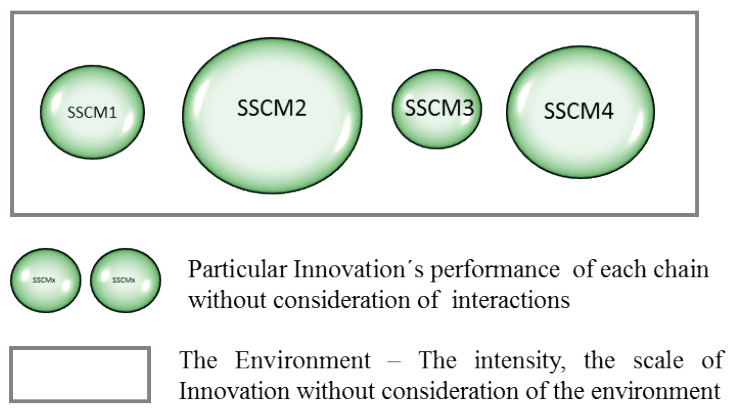

\section{System oriented approach to innovations}

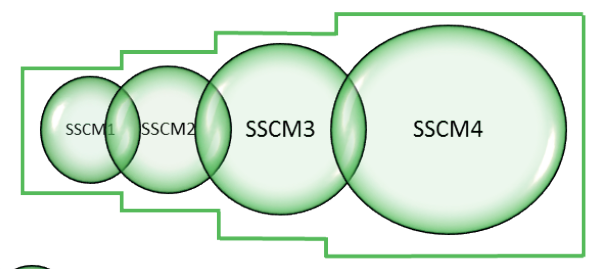

P1 - System Innovation's performance solving interactions - flow of active and passive components.

P2 - Properties of Sustainable environment which derives the performance of the Innovation of interactions.

Fig. 2 Traditional and environmental full system oriented approach to innovations in SSCM

The traditional attitude on the implementation of innovations is focused on the maximum performance (the lowest possible cost) of each individual element in the sustainable supply chain. This approach does not take into account the environment and consequences. All these circumstances, influencing the output of the whole supply chain dramatically, need to be considered. Particular optimization creates serious barriers to efficiency and effectiveness of the whole. 


\begin{tabular}{|c|c|c|c|}
\hline & Principles & Assumptions & EDC Pillars \\
\hline \multirow{12}{*}{$\begin{array}{c}\text { System } \\
\text { oriented } \\
\text { SSCM } \\
\text { innovations }\end{array}$} & \multirow{5}{*}{ P1 } & Utilization of modern ICTs & QCI, GTL \\
\hline & & Compatible AISs in the supply chain (supplier, forwarder, warehouses, assembly line) & QCI, GTL \\
\hline & & Vertical integration of the supply chain (supplier, forwarder, producer) & QCI, FOLAB, GTL \\
\hline & & Shared planning & FOLAB, GTL \\
\hline & & Shared information flow & FOLAB, GTL \\
\hline & \multirow{7}{*}{$\mathbf{P 2}$} & Reduction of negative impact on the natural environment $\left(\mathrm{CO}_{2}\right)$ & QCI, FOLAB, GTL, CNG \\
\hline & & Better working conditions & FOLAB, GTL, CNG \\
\hline & & Good delivery quality & QCI, FOLAB, GTL, CNG \\
\hline & & Reasonable costs & QCI, FOLAB, GTL \\
\hline & & Availability of reseources & QCI, GTL \\
\hline & & Agility & QCI, FOLAB, GTL \\
\hline & & Resillience & QCI, FOLAB, GTL \\
\hline
\end{tabular}

The analogy could be seen in any team sport, or more precisely world championship of the concrete sport. There are generally two teams at the end of the championship. The one, who defeats all the opponents during the tournament and the one, created from the best possible players on each individual position from all the participating teams during the tournament (as goalkeeper, defender, striker in football), all stars team. Which one would be working as a team better and whose performance creates better output? The one that could improve its interactions during the tournament, although the opponent could have a better individual player at each position. This example advocates the importance of interaction - the first principle of environmental full system oriented innovations in SSCM (P1).

The same example could be used for explaining the importance of the second principle (P2). As the coach of the team, should the same tactics be used - the performance of cooperation of all members of the team, against all opponents? Certainly not. The optimal performance of the team members' interaction needs to be derived from the qualitative properties of each individual opponent (better offensive skills, defensive skills, etc.), which means considering the environment.

Literature research and the consultation of its findings with automotive professionals enable to identify the best possible innovative solutions for the current supply chain in SAL. More efficient particular solutions than the ones used in EDC, could be found in the current technological world for each part of the supply chain interaction. However, the goal of system oriented innovations is not the maximal efficiency of particular parts (sustainability does not mean minimum costs + minimum $\mathrm{CO}_{2}$ production + minimum social negative impact of each chain in the SSCM) but the maximal performance of the whole system including the sustainable elements. The optimal output of EDC innovation could be reached and measured only as a whole, not only by evaluating the performance of particular parts and its interactions.

The detailed analysis of the four main pillars of the EDC enables to create the System Oriented SSCM Innovations (SOI) matrix, which combines the two principles and twelve assumptions necessary for successful system oriented innovation in SSCM (see Table 1). Significant improvements in interaction of the elements in SSCM are reached by EDC pillars utilizing ICTs (Information and Communications Technologies improving integration, interaction and cooperation between chains in supply chain), AIS (Automatic Identification Systems connecting the production resources without human support) and integration focusing on shared planning and information flow. The environment creating the upper system of SSCM derives the properties - performance of interactions. The triple bottom line: environmental, social and economic aspects are specified in the reduction of $\mathrm{CO}_{2}$, improving working conditions for employees and reasonable cost and delivery quality, availability of resources, agility and resilience corresponding with the requirements of final and semi-final customers of the automotive industry.

\section{Conclusion}

SKODA AUTO is currently one of the most successful companies of the Volkswagen group and SKODA AUTO Logistics belongs to the leaders in logistics and supply chain management innovations. One of the innovative concepts developed by SAL is the EDC. The concept is oriented to make interactions in the SSCM efficiently, quickly, smoothly and environmentally friendly. Based on the case study research it is evident, the connection of more subjects (supplier, forwarder and automotive producer with all of its departments) to an efficient whole - sustainable supply chain, requires implementation of two key principles. Focus on mutual interactions between particular elements of SSCM and the derivation of the performance of these interactions from the essential properties of the whole SSCM. The upper system, from which the SSCM system is a part of, creates business markets and society conditions for the $21^{\text {st }}$ Century. The combination of the principles and derivation of necessary assumptions for system oriented SSCM innovation can be presented as SOI matrix (see Table 1). 
Innovations are traditionally focused on improving particular interactions in supply chain processes. More efficient particular solutions, than used in the EDC concept, could be found for each part of the supply chain interaction in the case study in the current technological world. However, the effectiveness of the whole system - SSCM in the automotive industry is not composed of the best particular solutions. Innovations carried out by system thinking and sustainable attitude reached far better presented results, than innovation improving only particular parts, without considering of interactions and the environment. The proposed SOI matrix could be used in the inbound or outbound processes of the SSCM not only in the automotive industry.

\section{Acknowledgement}

This article and associated research was carried out as a part of the project financed by Internal Grant Agency of SKODA AUTO University No. SGS/2015/02.

\section{References}

[1] KOTZAB, H., SEURING, S., MULlER, M.; REINER, G.: Research Methodologies in Supply Chain Management. Heidelberg : Springer Science and Business Media, 2005.

[2] CHRISTOPHER, M., RYALS, L. J.: Supply Chain Becomes the Demand Chain. J. of Business Logistics, vol. 35, No.1, 2014, pp. 29-35.

[3] ACKOFF, R. L.: Ackoff's Best: His Classic Writings on Management. New York : John Wiley \& Sons. 1999.

[4] COUNCIL OF SUPPLY CHAIN MANAGEMENT PROFESSIONALS: CSCMP Supply Chain Management Definitions and Glossary, [cit. 14/06/2016], available from: https://cscmp.org/supply-chain-management-definitions[5] SIKDAR, S. K.: Sustainable Development and Sustainability Metrics. AIChE J., vol. 49, No. 8, 2003, pp. 1928-1932.

[6] GONCZ, E., SKIRKE, U., KLEIZEN, H., BARBER, M.: Increasing the Rate of Sustainable Change: A Call for a Redefinition of the Concept and the Model for its Implementation. J. of Cleaner Production, vol. 15, No. 6, 2007, pp. 525-37.

[7] ELKINGTON, J.: Enter the Triple Bottom Line. In Henriques, A.; Richardson, J. (Eds), The Triple Bottom Line: Does It All Add up? London: Earthscan, 2004, pp. 1-16.

[8] CARTER, C. R., EASTON, P. L.: Sustainable Supply Chain Management: Evolution and Future Directions. Intern. J. of Physical Distribution \& Logistics Management, vol. 41, No. 1, 2011, pp. 46-62.

[9] LUDWIG, C.: Audi Geo-Fencing Project Takes Top VW Group Logistics Prize, [cit. 23/08/2015]. Available from: http://www. automotivelogisticsmagazine.com/news/audi-geo-fencing-project-takes-top-vw-group-logistics-prize.

[10] SKODA AUTO: Annual Report 2014, [cit. 04/08/2015]. Available from: http://www.skoda-auto.com/en/company/investors/ annual-reports.

[11] VOLKSWAGEN: Implementation Guideline: Global Transport Label (GTL), [cit. 23/08/2015]. Available from: http://goo.gl/ OkRSvQ.

[12] Consumer Energy Center. Compressed Natural Gas (CNG) as a Transportation Fuel, [cit. 23/08/2015], available from: http:// www.consumerenergycenter.org/transportation/ afvs/cng.html.

[13] SKODA AUTO: TOP 50 Innovative Logistics Solutions in SKODA AUTO a. s., 2015. 